${ }^{1}$ Department of Restorative Dentistry, Operative Dentistry Division, Piracicaba Dental School, University of Campinas.
Corresponding author: Janaina Emanuela Damasceno Department of Restorative Dentistry, Piracicaba Dental School, University of Campinas

Av. Limeira, 901

13414-903

Piracicaba - SP - Brazil

e-mail: janaina.damasceno.

santos@gmail.com

Received: July 6, 2020

Accepted: March 03, 2021

Editor: Dr. Altair A. Del Bel Cury

\section{Conservative treatment of interproximal incipient caries lesions by resin infiltration}

\author{
Priscila Regis Pedreira ${ }^{1}$ (iD, Janaina Emanuela \\ Damasceno ${ }^{1, *}$ iD , Ana Ferreira Souza ${ }^{1}$ (iD, Gabriela \\ Alves de Cerqueira ${ }^{1}$, Flávio Henrique Baggio \\ Aguiar $^{1}$ (iD, Giselle Maria Marchi ${ }^{1}$ (iD
}

Minimally invasive dentistry is based on conservative techniques for the treatment of initial caries lesions, the so-called white spot lesions. One of the conservative maneuvers includes the use of enamel resin infiltrant: a low viscosity material that penetrates the enamel pores to stop lesion progression. Aim: Therefore, this case report aimed to describe the clinical case of a 28-year-old female patient under routine consultation, in which a radiographic examination showed the presence of two incipient caries lesions in the left upper premolars. Methods: The application of a resin infiltrating agent (Icon ${ }^{\circledR}, \mathrm{DMG}$ - Hamburg, Germany) was chosen as treatment to stop caries lesions progression. Conclusion: The use of this conservative technique can be considered a promising approach for the prevention of dental tissue wear, and the resin infiltrant is considered an effective material.

Keywords: Dental caries. Conservative treatment. Composite resins. 


\section{Introduction}

Behavioral habits, such as maintenance of oral hygiene and dietary control, are effective in the process of controlling caries disease progression, in addition to local fluoridation maneuvers ${ }^{1,2}$. However, despite their effectiveness, these maneuvers are more strongly indicated for lesions restricted to enamel in patients with less risk of caries, due to the great dependence on collaboration on the part of these ${ }^{1,2}$. Minimally Invasive Dentistry recommends early intervention approaches in the initial manifestations of caries disease to inhibit its progress, as well as acting preventively, aiming at the treatment of signs of the disease with maximum preservation of dental tissue ${ }^{3}$.

Dental caries is a multifactorial disease that has as dependent factors a diet rich in carbohydrates, in addition to the susceptibility of the host and the presence of a cariogenic microbial flora ${ }^{4}$. The process of constant reductions in oral $\mathrm{pH}$ disrupts the demineralization-remineralization cycle (De-Re), which constantly occurs in a balanced way in an oral health situation ${ }^{5}$. Acid by-products generated by bacterial activity cause localized destruction of dental tissues as they penetrate and diffuse through tissues, and, if this process is not controlled, it progresses to the first clinically visible manifestation of caries disease: white spot lesions ${ }^{6}$. These lesions appear morphologically with an apparently intact external surface, followed by a demineralized subsurface ${ }^{6}$. It begins with a small superficial demineralization and, with the advance of the etiological process, the acids reach the subsurface layer, while the external surface remains "intact"6.

Within the philosophy of conservative treatment, materials such as fissure sealants are used successfully, being indicated for application on newly erupted molars of young patients, due to the retentive anatomy of these teeth, which favors the bacterial accumulation on the occlusal surface ${ }^{7,8}$. A limitation of these materials, however, are interproximal caries lesions, which do not present any form of retention for sealants. Before this issue, the use of resin infiltrants has been proposed in Dentistry ${ }^{9}$.

Infiltrants are resinous materials of low viscosity, indicated for application in initial caries lesions located on flat dental surfaces ${ }^{10}$. Due to the characteristics of these lesions, which appear as a porous subsurface tissue under a mineralized pseudo-intact enamel layer ${ }^{6}$, these materials represent a promising alternative to prevent the wear of sound tooth tissue ${ }^{11}$. The mechanism of action of resin infiltrants occurs by the obliteration of the pores of the demineralized subsurface enamel, controlling the progression of the lesions by preventing the diffusion of bacterial products into these ${ }^{12}$, being considered materials of satisfactory effectiveness ${ }^{12,13}$. Its advantage, compared to conventional restorative treatment, is the preservation of dental tissue, to the detriment of the wear commonly necessary to gain access to interproximal caries lesions ${ }^{14}$, since its penetration into the interior of the lesion is due to capillarity forces $^{10}$, in addition to avoiding the beginning of the restorative cycle, since restorative procedures may require, in some cases, repair or replacement, especially in patients with a history of high caries activity ${ }^{15}$.

In view of the above, this article aimed to describe a clinical case using Icon ${ }^{\circledR}$ (DMG Hamburg, Germany) resin infiltrant in two interproximal caries lesions, focusing on the application protocol of the material used, discussing its inherent aspects. 


\section{Case Report}

A 28-year-old female patient sought the graduate clinic of the Faculty of Dentistry of Piracicaba for a routine consultation. The case reported was submitted to the ethics and research committee of the same Faculty, being approved under number: CAAE - 30541620.8.0000.5418. The clinical examination began and, after prophylaxis and visual inspection, no changes in the dental elements were observed (Fig.1). Interproximal radiography was then performed, and radiolucent lesions restricted to tooth enamel could be seen in two elements - on the distal 24 and mesial 25 surfaces (Fig.2). Due to the characteristics of the lesions, the treatment with enamel resin infiltrant was chosen.

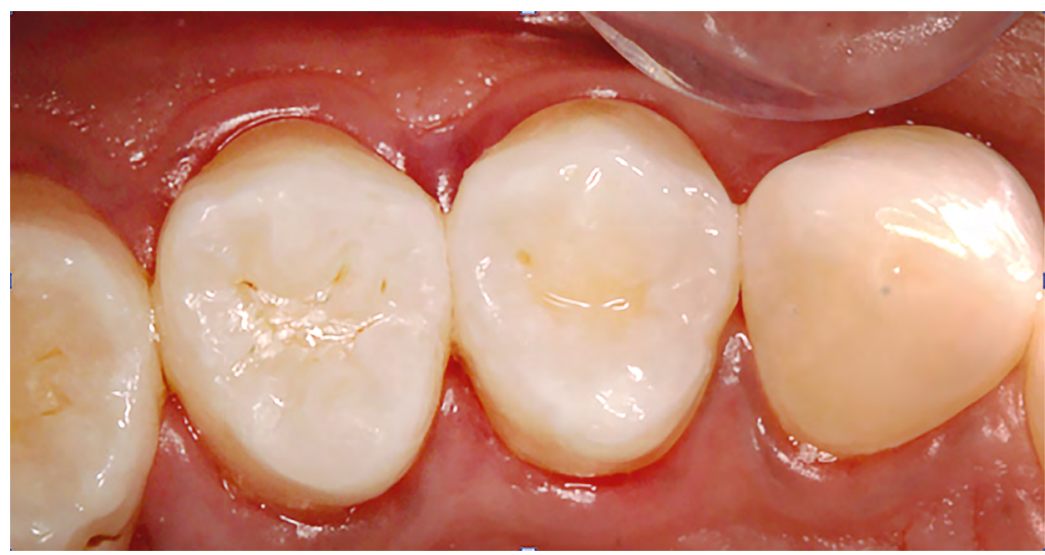

Figure 1. Initial clinical appearance

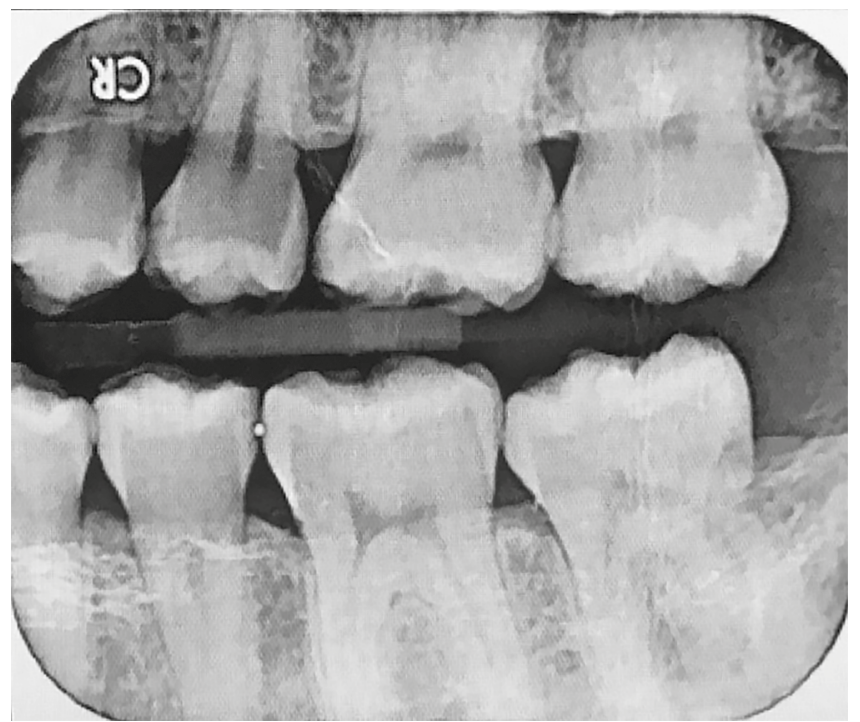

Figure 2. Diagnosis by interproximal radiography 
The procedure was started with absolute isolation. Then, the interproximal wedge was inserted (Fig.3a) to create space between the dental elements 24 and 25 and allow the stabilization of the applicator tips. It was decided to start the procedures on the distal face of element 24. Thus, following all the manufacturer's recommendations, Icon ${ }^{\circledR}$ Etch (composed of $15 \%$ hydrochloric acid - $\mathrm{HCl}$ ) was applied (Fig.3b) to increase the permeability of the enamel surface. It remained on the surface for 2 minutes and was then removed with a jet of water for 30 seconds, followed by drying with air for 30 seconds (Fig,3c). Then, Icon ${ }^{\circledR}$ Dry was applied for 30 seconds (Fig.3d), twice, followed by drying with air for 30 seconds. Finally, the application of the infiltrant itself, Icon ${ }^{\circledR}$ Infiltrant, was carried out, which remained in contact with the dental surface for 3 minutes (Fig.3e). The matrix was removed, and the excess material was removed with dental floss, followed by photoactivation for 40 seconds (Radii Plus, SDI Brasil Industria e Comercio LTDA, São Paulo, SP - Brazil) on each dental face (Fig.3f). As indicated by the manufacturer, a second application of Icon ${ }^{\circledR}$ Infiltrant was performed, this time for only 1 minute, without the need to repeat the previous steps, to ensure the diffusion of the material throughout the extension of the lesion and, consequently, to seal marginal surface pores.
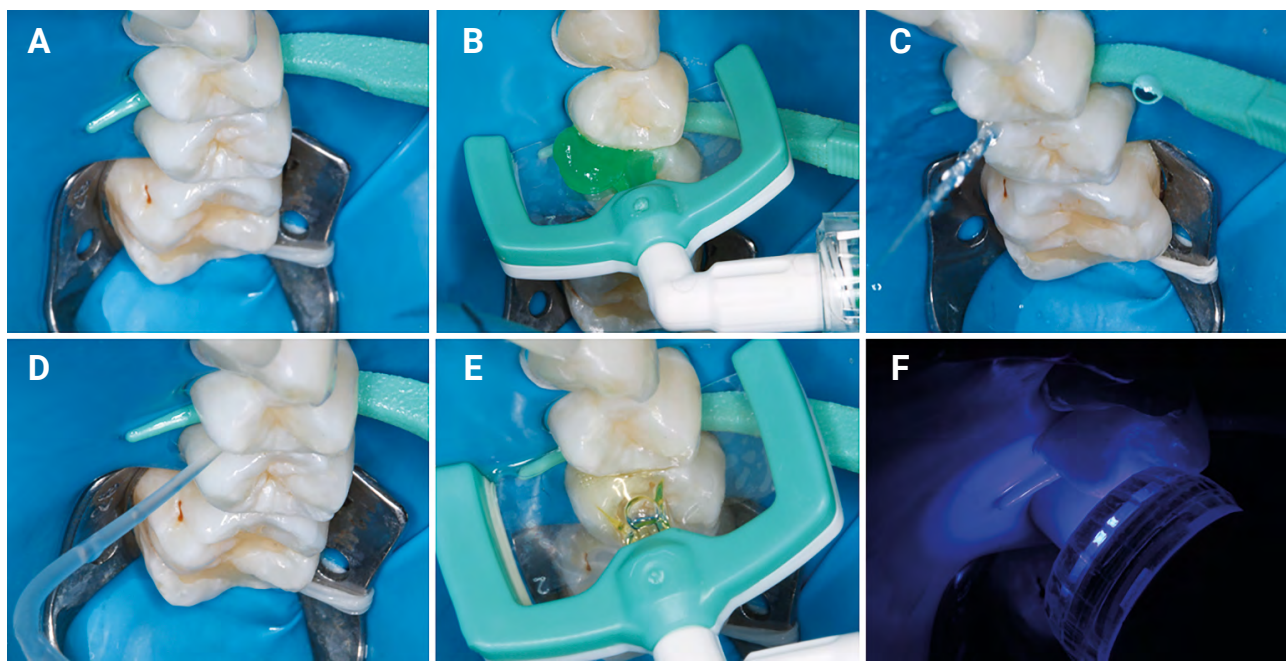

$\mathbf{F}$

Figure 3. Protocol of the application for the resinous infiltrant Icon ${ }^{\circledR}$ 
The same protocol applied for element 24 was performed for the treatment of element 25. Follow-up was performed by an interproximal radiographic examination, after 18 months of application (Fig.4).

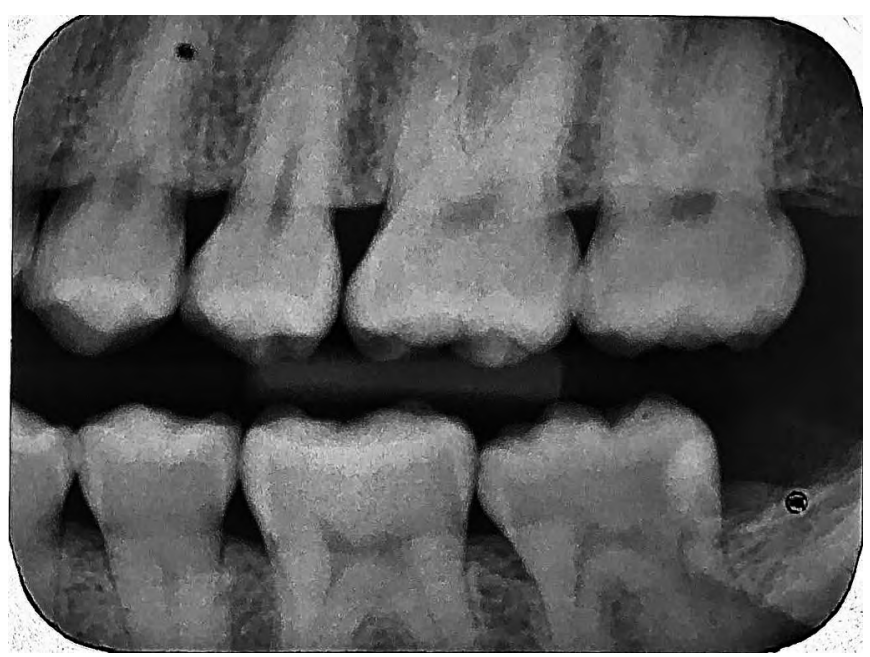

Figure 4. Follow-up after 18 months of the radiographic aspect.

\section{Discussion}

The trend towards minimally invasive dentistry has expanded the treatment possibilities for carious dental lesions and the knowledge currently available. The advancement of products and techniques allows for the use of more conservative strategies for incipient and non-cavitated lesions ${ }^{16}$, including the application of Icon ${ }^{\circledR}$ infiltrant. In view of the above, the treatment for initial carious lesions with Icon ${ }^{\circledR}$ Infiltrant was proposed to the patient of this clinical case, which does not require cavity preparation.

Regarding the development of caries disease, a balanced De-Re cycle is responsible for maintaining the integrity of hard dental tissues because, in this situation, there is no loss or gain of minerals ${ }^{5}$. However, the bacteria contained in the biofilm are metabolically active all the time and, because of the disposition of fermentable carbohydrates, they generate by-products that alter the oral $\mathrm{pH}$ to intensify demineralization and hinder remineralization, leading to the development of caries lesions ${ }^{5}$. Lesions of dental tissues are considered signs of caries disease and may be present at an ultrastructural level, i.e., not be visible on clinical examination until total destruction of dental tissues ${ }^{6,17}$. In this clinical case, the patient did not present symptoms or detectable clinical signs, and it was possible to visualize incipient caries lesions only by radiographic examinations during the routine consultation.

The philosophy of minimal intervention advocates the use of conservative treatments to minimize the loss of dental tissues. Thus, prevention and early intervention in caries injury are the first approaches ${ }^{18}$. The treatment of incipient lesions begins with etiological factors, i.e., oral hygiene and dietary control, to reestablish the De-Re balance 
and enable the remineralization of the lesions ${ }^{19}$. The patient in this case reported a balanced diet concerning carbohydrates and presented good oral hygiene, without plaque accumulation; however, there was a deficiency in the use of dental floss. Therefore, corroborating the literature ${ }^{19}$, the dentist reinforced to the patient all care about oral feeding and hygiene, motivating her regarding the need for regular flossing.

However, only the control of etiological factors may not be able to promote the remineralization of initial caries lesions in some situations, especially in the case of interproximal regions, which represent areas that require greater discipline from patients concerning hygiene ${ }^{20}$. Another treatment option is the topical applications of fluoride, which is also highly dependent on the patient's adherence to the return visits to the dental office ${ }^{21}$. In this context, it was decided to treat the incipient caries lesions with resin infiltrant, since the material is able to interrupt the progression of the lesions, as well as seal the marginal surface, besides having its application performed in a single clinical session and not requiring return visits over a short period of time, as is the case with topical fluoride application ${ }^{22}$

The literature reports several advantages of the resin infiltration technique: mechanical stabilization of demineralized enamel, sealing of surface pores and enamel areas with deeper demineralization, preservation of dental enamel and paralysis of progression of the lesion, increased resistance to demineralization, minimal risk of development of secondary caries, and high patient acceptance ${ }^{23,24}$.

A limitation of commercially available resin infiltrant, however, is the fact that it does not present radiopacity, which is an essential property for detecting the contour of the restorations and the depth of penetration of the infiltrant in the injury, for example ${ }^{25}$. Thus, the control of the stabilization of the lesion is possible by the performance of radiographic control takes. In this case, the follow-up of the treatment of white spot lesions infiltrated with Icon $^{\circledR}$ was performed by interproximal radiographic examination 18 months after the application of the product. The paralysis of caries lesions was observed by comparing the final and initial radiographic images (diagnosis) of the treatment, which showed no progression of the lesions.

Several reports in the literature indicate the efficacy of infiltrants in controlling the progression of caries disease. A clinical study ${ }^{11}$, which compared the evolution of interproximal enamel lesions treated or not with resin infiltrant, in which all patients received guidance regarding oral hygiene care, obtained as a result, after 18 months follow-up, a reduced progression of caries in treated groups compared to the untreated control group, concluding that infiltration is an effective treatment to reduce lesion progression. Another investigation ${ }^{26}$ obtained satisfactory penetration depth results and a statistically significant increase in microhardness values of enamel surface lesions after infiltration, indicating infiltrants as a valid treatment option for non-cavitated lesions.

It is known that white spot injury is porous and, when exposed to constant acid challenges, can become cavitated. However, this type of injury can also be paralyzed or remineralized ${ }^{16,27}$, and thus modern dentistry has focused on early intervention to reduce patient damage and loss of dental tissue, succeeding in these new approaches.

In conclusion, the treatment of incipient caries lesions by the application of the enamel resin infiltrant Icon ${ }^{\circledR}$ has achieved positive results, corroborating minimally invasive dentistry, besides presenting good acceptance by the patient. 


\section{Acknowledgments}

The authors thank Espaço da Escrita - Pró-Reitoria de Pesquisa - UNICAMP - for the language services provided.

\section{Conflicts of Interest Statement}

\section{The authors report no conflicts of interest in this case report.}

\section{References}

1. Vanderas AP, Gizani S, Papagiannoulis L. Progression of proximal caries in children with different caries indices: a 4-year radiographic study. Eur Arch Paediatr Dent. 2006 Sep;7(3):148-52. doi: 10.1007/BF03262556.

2. Vanderas AP, Manetas C, Koulatzidou M PL, Papagiannoulis L. Progression of proximal caries in the mixed dentition: a 4-year prospective study. Pediatr Dent. 2003 May-Jun;25(3):229-34.

3. Skucha-Nowak M, Gibas M, Tanasiewicz M, Twardawa H, Szklarski T. Natural and controlled demineralization for study purposes in minimally invasive dentistry. Adv Clin Exp Med. 2015;24(5):891-8. doi: 10.17219/acem/28903.

4. Cury, JA; Tenuta LM. Enamel remineralization: controlling the caries disease or treating early caries lesions? Dental caries: the disease and its signals Enamel remineralization. Braz Oral Res. 2009;23 Suppl 1:23-30. doi: 10.1590/s1806-83242009000500005.

5. Moreno EC, Zahradnik RT. Demineralization and remineralization of dental enamel. J Dent Res. 1979 Mar;58(Spec Issue B):896-903. doi: 10.1177/00220345790580024301.

6. Kidd EAM, Fejerskov O. What constitutes dental caries? Histopathology of carious enamel and dentin related to the action of cariogenic biofilms. J Dent Res. 2004;83 Spec No C:C35-8. doi: 10.1177/154405910408301s07.

7. Ahovuo-Saloranta A, Forss H, Walsh T, Nordblad A, Mäkelä M, Worthington H V. Pit and fissure sealants for preventing dental decay in permanent teeth. Cochrane Database Syst Rev. 2017 Jul;7(7):CD001830. doi: 10.1002/14651858.CD001830.pub5.

8. Berger S, Goddon I, Chen CM, Senkel H, Hickel R, Stösser L, et al. Are pit and fissure sealants needed in children with a higher caries risk? Clin Oral Investig. 2010 Oct;14(5):613-20. doi: 10.1007/s00784-009-0343-8.

9. Paris S, Soviero VM, Seddig S, Meyer-Lueckel H. Penetration depths of an infiltrant into proximal caries lesions in primary molars after different application times in vitro. Int J Paediatr Dent. 2012 Sep;22(5):349-55. doi: 10.1111/j.1365-263X.2011.01204.x.

10. Meyer-Lueckel H, Paris S. Progression of artificial enamel caries lesions after infiltration with experimental light curing resins. Caries Res. 2008;42(2):117-24. doi: 10.1159/000118631.

11. Paris S, Hopfenmuller W, Meyer-Lueckel H. Resin infiltration of caries lesions: An efficacy randomized trial. J Dent Res. 2010 Aug;89(8):823-6. doi: 10.1177/0022034510369289.

12. Paris S, Meyer-Lueckel H. Infiltrants inhibit progression of natural caries lesions in vitro. J Dent Res. 2010 Nov;89(11):1276-80. doi: 10.1177/0022034510376040.

13. Meyer-Lueckel H, Bitter K, Paris S. Randomized Controlled Clinical Trial on Proximal Caries Infiltration: three-Year. Caries Res. 2012;46(6):544-8. doi: 10.1159/000341807.

14. Vila Verde A, Ramos MMD, Stoneham AM. Benefits in cost and reduced discomfort of new techniques of minimally invasive cavity treatment. J Dent Res. 2009 Apr;88(4):297-9. doi: $10.1177 / 0022034509334157$. 
15. Qvist V. Longevity of restorations: the 'death spiral'. In: Fejerskov OKE, editor. Dental caries: the disease and its clinical management. $2^{\text {nd }}$ ed. Oxford: Blackwell Munksgaard; 2008. p.443-56.

16. Kidd E. The implications of the new paradigm of dental caries. J Dent. 2011 Dec;39 Suppl 2:S3-8. doi: 10.1016/j.jdent.2011.11.004.

17. Clark CA, Fintz JB, Taylor R. Effects of the control of plaque on the progression of dental caries: results after 19 months. J Dent Res. 1974;53(6):1468-74. doi: 10.1177/00220345740530062901.

18. Peters MC. Strategies for noninvasive demineralized tissue repair. Dent Clin North Am. 2010 Jul;54(3):507-25. doi: 10.1016/j.cden.2010.03.005.

19. Paula ABP, Fernandes AR, Coelho AS, Marto CM, Ferreira MM, Caramelo F, et al. Therapies for white spot lesions-a systematic review. J Evid Based Dent Pract. 2017 Mar;17(1):23-38. doi: 10.1016/j. jebdp.2016.10.003.

20. Ashwath B, Vijayalakshmi R, Arun D, Kumar V. Site-based plaque removal efficacy of four branded toothbrushes and the effect of dental floss in interproximal plaque removal: a randomized examiner-blind controlled study. Quintessence Int. 2014;45(7):577-84. doi: 10.3290/j.qi.a31960.

21. Lindhe J, Axelsson P. The effect of controlled oral hygiene and topical Euoride application on caries and gingivitis in Swedish schoolchildren. Community Dent Oral Epidemiol. 1973;1(1):9-16. doi: 10.1111/j.1600-0528.1973.tb01056.x.

22. Lasfargues JJ, Bonte E, Guerrieri A, Fezzani L. Minimal intervention dentistry: Part 6. Caries inhibition by resin infiltration. Br Dent J. 2013 Jan;214(2):53-9. doi: 10.1038/sj.bdj.2013.54.

23. Schwendicke F, Meyer-Lueckel H, Stolpe M, Dorfer CE, Paris S. Costs and effectiveness of treatment alternatives for proximal caries lesions. PLoS One. 2014 Jan 27;9(1):e86992. doi: 10.1371/journal. pone.0086992.

24. Anauate-Netto C, Borelli L Neto, Amore R, DI Hipólito V, D'Alpino PHP. Caries progression in non-cavitated fissures after infiltrant application: a 3-year follow-up of a randomized controlled clinical trial. J Appl Oral Sci. 2017;25(4):442-54. doi: 10.1590/1678-7757-2016-0633.

25. Saridag S, Helvacioglu-yigit D, Alniacik G, Özcan M. Radiopacity measurements of direct and indirect resin composites at different thicknesses using digital image analysis. Dent Mater J. 2015;34(1):13-8 doi: 10.4012/dmj.2014-181.

26. Prajapati D, Nayak R, Pai D, Upadhya N, Bhaskar VK, Kamath P. Effect of resin infiltration on artificial caries: an in vitro evaluation of resin penetration and microhardness. Int J Clin Pediatr Dent. 2017 Jul-Sep;10(3):250-6. doi: 10.5005/jp-journals-10005-1445.

27. Ferreira Zandoná A, Santiago E, Eckert GJ, Katz BP, Pereira de Oliveira S, Capin OR, et al. The natural history of dental caries lesions: a 4-year observational study. J Dent Res. 2012 Sep;91(9):841-6. doi: 10.1177/0022034512455030. 